\title{
Management of Small Unruptured Intracranial Aneurysms: A Survey of Neuroradiologists
}

\author{
(D) A. Malhotra, (D)X. Wu, (D)B. Geng, (DD. Hersey, (DD. Gandhi, and (D)P. Sanelli
}

\begin{abstract}
BACKGROUND AND PURPOSE: The long-term history and management of unruptured intracranial aneurysms is not well understood. Our aim was to determine current practice patterns in the management of unruptured intracranial aneurysms, especially regarding imaging surveillance for conservatively managed aneurysms of this type.
\end{abstract}

MATERIALS AND METHODS: An on-line survey was designed to examine physician practice and preference regarding the management of small unruptured intracranial aneurysms ( $\leq 7 \mathrm{~mm}$ in diameter). The survey was circulated to members of the American Society of Neuroradiology. Participation was voluntary, and all responses were anonymous.

RESULTS: A total of 227 individual survey responses were obtained and included in the analysis with 54.6\% (124/227) from diagnostic neuroradiologists (practicing $>50 \%$ neuroradiology) and one-third (29\%) from neurointerventional radiologists. One hundred seventythree of 227 responded that routine, periodic imaging surveillance would be appropriate for conservatively managed unruptured intracranial aneurysms, and $84 \%$ of respondents recommended surveillance frequency of at least once a year. Fifty-nine percent favored indefinite, life-long follow-up for small unruptured intracranial aneurysms, and a similar number of respondents favored noncontrast MR angiography for aneurysm follow-up. Significant heterogeneity was found in size measurements used to assess aneurysms and criteria used to define growth on surveillance imaging.

CONCLUSIONS: The natural history of intracranial aneurysms is not well-understood. A large proportion of incidentally detected, unruptured aneurysms are small $(<7 \mathrm{~mm})$. The survey results show significant heterogeneity in practice even among neuroradiologists and underlies the need to standardize imaging practice. Further studies are needed to assess the optimal frequency and duration of surveillance imaging for unruptured intracranial aneurysms. The criteria used to measure aneurysms and define growth on imaging also need to be standardized.

ABBREVIATIONS: $\mathrm{AHA}=$ American Heart Association; $\mathrm{ASA}=$ American Stroke Association; UIA = unruptured intracranial aneurysm

$\mathbf{U}^{n}$ nruptured intracranial aneurysms (UIAs) are relatively common in the general population, found in approximately $3.2 \%$ of the adult population worldwide. ${ }^{1}$ They are being increasingly diagnosed due to more frequent use of less invasive imaging tech-

Received September 29, 2017; accepted after revision January 3, 2018.

From the Department of Radiology and Biomedical Imaging (A.M.), Yale School of Medicine, New Haven, Connecticut; Yale School of Medicine (X.W., B.G.), New Haven, Connecticut; Clinical Information Services (D.H.), Cushing/Whitney Medical Library, Yale University, New Haven, Connecticut; Department of Interventional Neuroradiology (D.G.), University of Maryland School of Medicine, Baltimore, Maryland; and Department of Radiology (P.S.), Northwell Health, New York, New York.

Please address correspondence to Ajay Malhotra, MD, MMM, Department of Radiology and Biomedical Imaging, Yale School of Medicine, Box 208042, Tompkins East 2, 333 Cedar St, New Haven, CT 06520-8042; e-mail: ajay.malhotra@yale.edu; @cea_yale

三 Indicates article with supplemental on-line table.

Indicates article with supplemental on-line photos.

http://dx.doi.org/10.3174/ajnr.A5631 niques with higher resolution. ${ }^{2}$ The optimal management of UIAs should be decided on the basis of their natural history, which remains poorly understood. ${ }^{3-5}$ Observational studies of UIAs suggest that only a fraction of them rupture, though these data have high selection bias, with high-risk aneurysms being treated, resulting in potential underestimation of the rupture rate. ${ }^{6,7} \mathrm{An}$ eurysm size is considered the major risk factor for UIA rupture, with low reported rates of rupture in small $(<7 \mathrm{~mm})$ aneurysms. ${ }^{6}$ A high proportion of unruptured aneurysms are small $(<7 \mathrm{~mm}$ in diameter) and incidental. ${ }^{8-10}$ Studies have reported that up to $87.6 \%$ of incidental UIAs are tiny, measuring $<3-4 \mathrm{~mm} .{ }^{9}$ However, small aneurysms are known to rupture, and some recent studies have reported that up to a third of ruptured intracranial aneurysms measure $<5 \mathrm{~mm} .{ }^{9,11}$ An increasing number of treating physicians favor preventive treatment of even tiny aneurysms. $^{12,13}$

The American Heart Association/American Stroke Associa- 
tion (AHA/ASA) guidelines for management of patients with UIAs were updated in $2015 .^{8}$ However, these do not specify separate recommendations for small $(3-7 \mathrm{~mm})$ and tiny aneurysms ( $\leq 3 \mathrm{~mm}$ ), though their natural history, risk of rupture, and success of treatment might be different from aneurysms measuring $>7 \mathrm{~mm} .{ }^{3,6,14}$ Patients with no history of SAH with aneurysms of $\leq 7 \mathrm{~mm}$ are often followed conservatively with imaging surveillance to assess changes in size and/or morphology, which are known to predict rupture. ${ }^{15,16}$ The AHA/ASA guidelines recommend radiographic follow-up with MRA or CTA at regular intervals. However, the interval and duration of recommended followups are uncertain (Class I; Level of Evidence B). ${ }^{8}$

This lack of clarity in guidelines is reflective of the heterogeneity in the current literature in the preferred imaging technique for surveillance and the best imaging criteria to assess growth. ${ }^{3,17} \mathrm{We}$ undertook this survey to assess the practice patterns among diagnostic and interventional neuroradiologists in the surveillance and management of UIAs, particularly small UIAs. To our knowledge, no recent studies have defined current clinical imaging practice to quantify and understand the variability in practice patterns in clinical care.

\section{MATERIALS AND METHODS}

A 12-question on-line survey was designed to examine physician practices and preferences regarding the surveillance and management of small UIAs ( $\leq 7 \mathrm{~mm}$ in diameter). The survey was performed using the Qualtrics Survey Software (Qualtrics, Provo, Utah), a Web-based system for surveys. Approval was obtained from the American Society of Neuroradiology to distribute the on-line survey through e-mails to their members soliciting survey completion. A single-click link to the survey was attached. Participation was voluntary, and no compensation was offered to participants. All responses were anonymous. Qualtrics software records the Internet Protocol address, therefore limiting respondents to a single response. The survey was open for 6 weeks. All survey results were summarized and reported by Qualtrics.

All survey results were compiled and graphed using Qualtrics. Using the $\chi^{2}$ test, we additionally explored the differences in responses between diagnostic neuroradiologists and neurointerventional radiologists/endovascular surgeons in growth measurements, growth definition, and factors that lead to treatment decisions.

\section{RESULTS}

A total of 227 individual survey responses were obtained and included in the analysis. The full list of questions and respondent answers is in the On-line Table.

\section{Respondent Characteristics}

Most respondents, 54.6\% (124/227), were diagnostic neuroradiologists (practicing $>50 \%$ neuroradiology), while $7.5 \%$ (17/227) were fellowship-trained diagnostic neuroradiologists practicing $<50 \%$ neuroradiology. Almost one-third (29\%) were neurointerventional radiologists (On-line Fig 1). Regarding practice setting, $45 \%$ of respondents practiced in academic, tertiary care settings, with $29 \%$ in private practice and $20 \%$ in hybrid practice settings (combined academic and community setting).

\section{Prevalence of UIAs}

Regarding the frequency of small ( $<7 \mathrm{~mm}$ ) aneurysms among all UIAs in clinical practice, the opinion was split in the following manner: Thirty-four percent of respondents thought that small aneurysms constituted $51 \%-75 \%$ of all aneurysms, $26 \%$ of respondents favored $>75 \%$ of all UIAs, $20 \%$ selected the $26 \%-50 \%$ category, while $19 \%$ thought they were $<25 \%$ of all UIAs (Online Fig 2).

\section{Rupture Rate in Aneurysms (>1 Option Allowed)}

Most respondents (209/227) opined that growing aneurysms are at much higher risk for rupture, irrespective of size. Very few $(11 / 227)$ responded that the aneurysmal rupture rate is uniform irrespective of size. Forty-four respondents answered that UIAs usually rupture many years ( $>10$ years) after they form or are discovered. Only 14/227 participants thought that treatment (clipping or coiling) eliminated any chance of subsequent subarachnoid hemorrhage.

\section{Management of Small UIAs (>1 Option Allowed)}

Nearly half the respondents $(n=101)$ commented that small UIAs should be routinely treated with clipping or coiling. One hundred seventy-three of 227 responded that routine, periodic imaging surveillance would be appropriate; 46/227 thought that only high-risk aneurysms needed treatment or imaging follow-up (such as growing aneurysms). A very small minority (2 participants) thought that no imaging follow-up was needed. Forty-seven of 227 responded that the frequency and duration should be similar in ruptured and unruptured aneurysms (Fig 1).

\section{Imaging Surveillance: Frequency of Conservatively Followed Small UIAs}

More than half of the respondents (52\%) thought that the appropriate imaging surveillance frequency should be every 6 months for the first year, followed by annual imaging thereafter. Thirtytwo percent thought annual imaging would be more appropriate. Biannual imaging was favored by $12 \%$, while $<1 \%$ opted for imaging follow-up every 5 years. More aggressive imaging follow-up (every 6 months) was chosen by $3 \%$ of the respondents.

\section{Imaging Surveillance: Duration of Conservatively Followed Small UIAs}

Most physicians (59\%) favored indefinite, life-long follow-up for small UIAs; $8.5 \%$ opted for 10 -year, $21 \%$ opted for 5 -year, and $12 \%$, for 2-year follow-up duration for conservatively followed small UIAs (Fig 2).

\section{Imaging Techniques for Conservatively Followed Small UIAs}

MR angiography without contrast using a time-of-flight technique was favored by $58 \%$, while contrast MRA was chosen by roughly $10 \%$ of respondents. Twenty-one percent chose CT angiography, and $3.2 \%$ chose DSA as the technique to follow small UIAs; $8.3 \%$ thought that any of these imaging modalities would be equally appropriate for surveillance. 


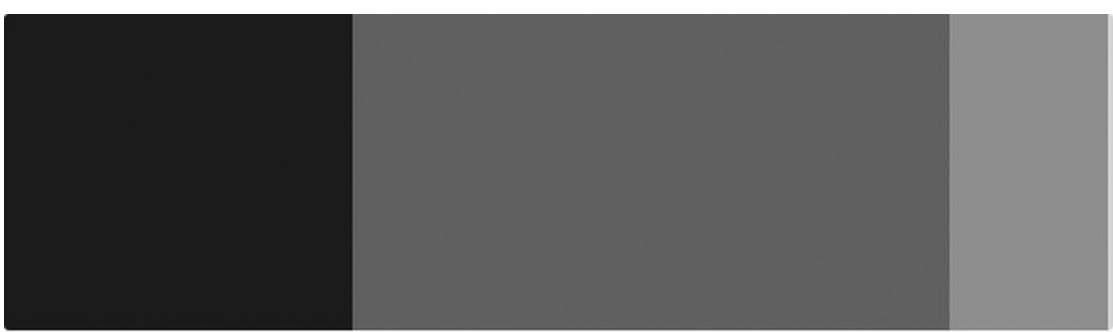

Routine treatment (clipping or coiling) should be considered $(31 \%, 101)$

Routine, periodic imaging surveillance would be appropriate $(54 \%, 173)$

Only high risk aneurysms need treatment or imaging follow-up (such as growing aneurysms) $(14 \%, 46)$

No imaging follow-up is needed $(1 \%, 2)$

FIG 1. Survey result of management of small UIAs.

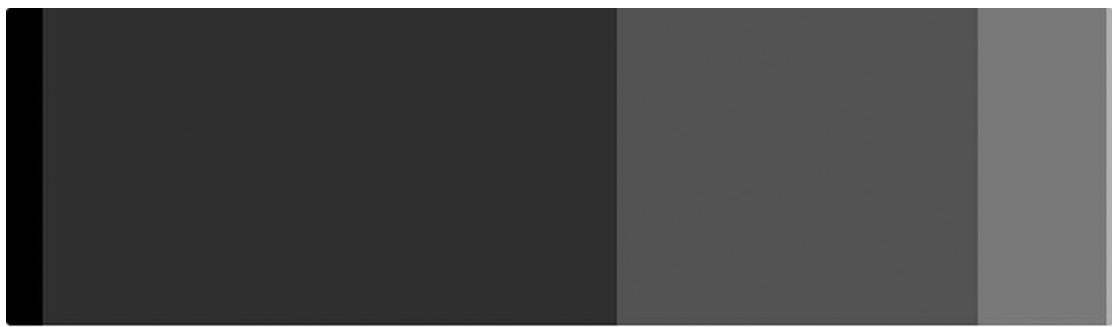

Every 6 months $(3 \%, 7)$

Every 6 months for first year, followed by annual imaging $(52 \%, 110)$

$$
\text { Biannual-every } 2 \text { years }(12 \%, 25) \text { Every } 5 \text { years }(1 \%, 2)
$$

FIG 2. Survey result of imaging follow-up frequency.

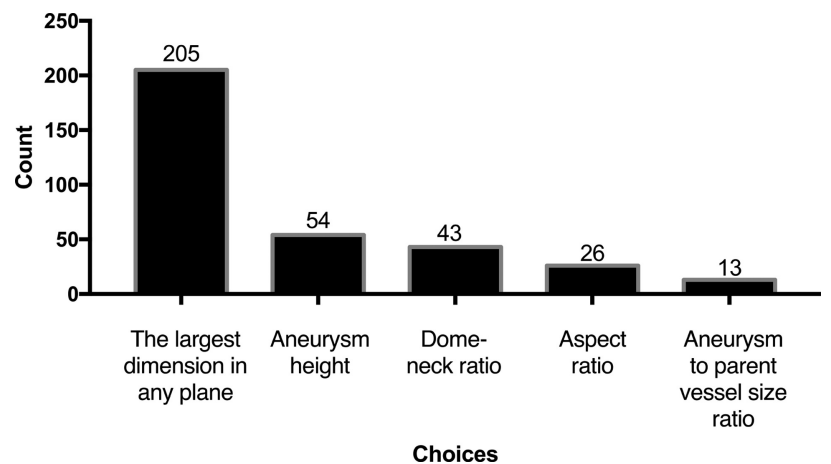

FIG 3. Survey result of measurement of aneurysmal growth.

\section{Preferred Measurement of Aneurysm on Surveillance Imaging (>1 Option Allowed)}

The largest dimension in any plane was most frequently used (205/227) followed by aneurysm height (54 participants). Dometo-neck ratio was chosen by 43 , and aspect ratio (aneurysm height divided by aneurysm neck), by 26 respondents. A small minority $^{13}$ reported using size ratio (aneurysm-to-parent vessel size ratio) (Fig 3). There was no significant difference in responses be-
Annual $(32 \%, 69)$

tween diagnostic neuroradiologists and neurointerventional radiologists/endovascular neurosurgeons to any of the choices.

\section{Criteria Used to Define Growth in Small UIAs (>1 Option Allowed)}

The most frequently used criterion for growth was growth of $>1 \mathrm{~mm}$ in at least in 1 direction in 166/227 responses. Fortythree chose growth of the aneurysm of $>1.5$ times its baseline measurement, while 37 chose an increase of $>0.5 \mathrm{~mm}$ in 1 dimension. An increase in volume of $>5 \%$ was used by 18 , and 12 chose a change in size to the nearest tenth of a millimeter more than the measurement error per manufacturer's specifications (Fig 4). There was no significant difference in responses between diagnostic neuroradiologists and neurointerventional radiologists/endovascular neurosurgeons.

High-Risk Patients Appropriate for Routine Screening (>1 Option Allowed)

One hundred ninety-five survey participants selected adult polycystic kidney disease, while 169 chose prior history of $\mathrm{SAH}$ as an appropriate criterion for screening. Patients with a family member with an unruptured aneurysm was the choice selected by 150 , while only 38 thought that patients with ascending aortic aneurysms should be screened for intracranial aneurysms (Fig 5).

\section{Criteria Used to Treat Small UIAs (>1 Option Allowed)}

Change in size $(n=215)$, change in morphology $(n=205)$, and complex morphology $(n=195)$ were the criteria most frequently selected for the decision to treat UIAs. Patient preference was chosen by 170 , and patient age, by 137 respondents. Smoking history was considered important by 95 , and sex, by 32 responding physicians (Fig 6). A statistically significant proportion of neurointerventional radiologists/endovascular neurosurgeons chose age and smoking history compared with diagnostic neuroradiologists.

\section{DISCUSSION}

To our knowledge, this survey of practicing neuroradiologists and neurointerventionalists is the first of its kind to assess and quantify practice patterns regarding small unruptured aneurysms. A high degree of respondent variability is evident regarding the perception of prevalence of small UIAs, preferred imaging technique for surveillance, frequency and duration for surveillance, and optimal criteria on imaging to assess aneurysm growth and rupture risk. 


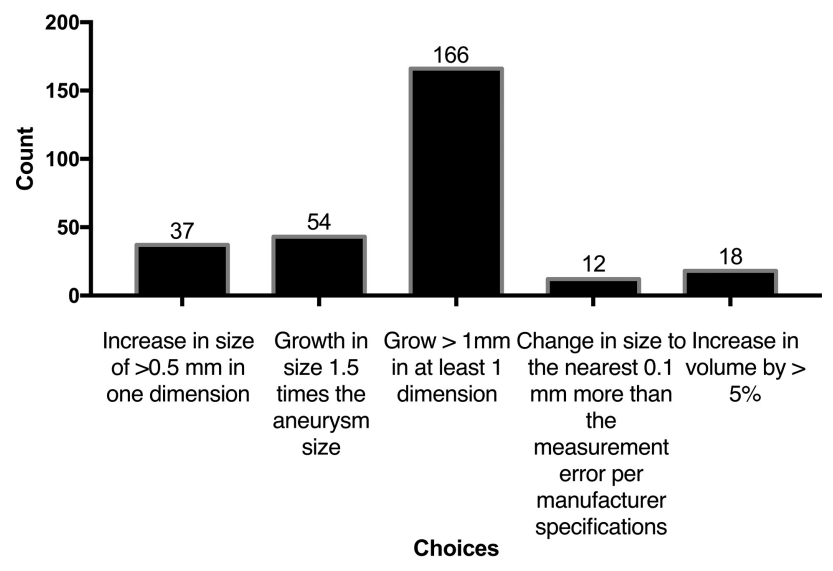

FIG 4. Survey result of the definition of aneurysmal growth.

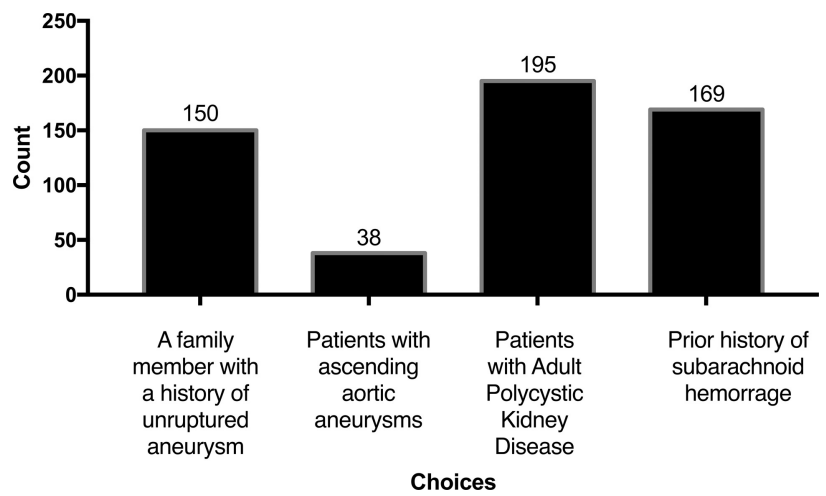

FIG 5. Survey result of the definition of high-risk patients.

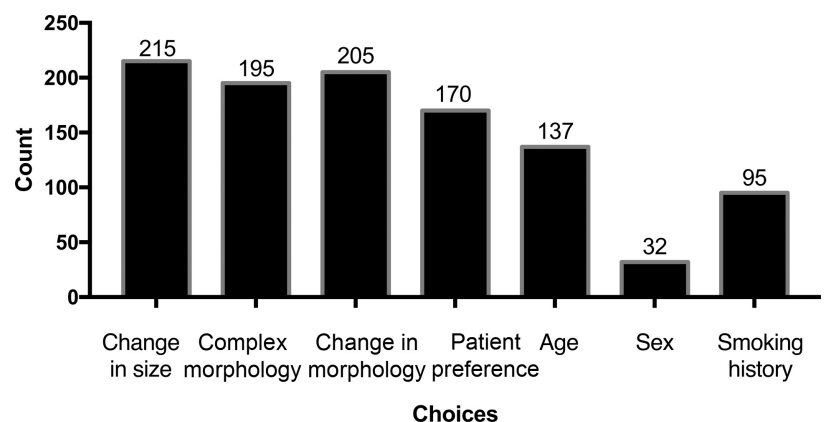

FIG 6. Survey result of factors determining treatment options.

Intracranial aneurysms are acquired lesions, and rupture is the most common etiology of nontraumatic SAH. ${ }^{4,18}$ However, rupture is uncommon and only occurs in 1 of 200-400 patients with a UIA per year. ${ }^{5}$ The natural history of UIAs remains poorly understood, especially for the smaller $(3-7 \mathrm{~mm})$ and tiny $(\leq 3 \mathrm{~mm})$ aneurysms. ${ }^{19}$

A meta-analysis in 2011 including 68 studies reported a prevalence of $3.2 \%(95 \% \mathrm{CI}, 1.9 \%-5.2 \%)$ in a population without comorbidity and a mean age of 50 years. ${ }^{1}$ However, a higher prevalence of up to $7 \%$ has been reported in more recent studies using MRA, with a higher prevalence in women and with increasing age. $^{20}$

Regarding the prevalence of small UIAs, the survey results indicated significant heterogeneity in opinions: Nearly $40 \%$ of respondents thought small $(<7 \mathrm{~mm}$ ) aneurysms constituted $<50 \%$ of all UIAs. According to a recent review, $93 \%$ of UIAs in adults are $<10 \mathrm{~mm}$ and $66 \%$ are $<5 \mathrm{~mm}$. ${ }^{1}$

Most respondents agreed that size was an important predictor of rupture, and growing aneurysms are at a higher risk for rupture. Size and location of UIAs have been recognized as predictors of rupture in prospective studies of UIAs. ${ }^{6,7,21}$ The International Study of Unruptured Intracranial Aneurysms (ISUIA) reported no ruptures among aneurysms of $<7 \mathrm{~mm}$ in the anterior circulation in patients with no history of SAH. ${ }^{6}$ However, as with most observational studies on UIAs, the ISUIA has some shortcomings, particularly related to the selection bias resulting from ablation of UIAs thought to be at high risk and conservative treatment of patients thought to be at lower risk of rupture, as well as a poor retention rate of patients used to define the natural history of aneurysms. Only $21 \%$ of patients in the observational group were followed up for $>4$ years. An increased risk of rupture of larger aneurysms, particularly in those measuring $>7 \mathrm{~mm}$ in diameter, has been reported. $6,9,21,22$

For assessing growth, 76\% (173/227) considered that routine, periodic imaging surveillance would be appropriate for UIAs managed conservatively. Studies have proposed imaging follow-up of all aneurysms (including those of $<7 \mathrm{~mm}$ ) due to up to a 12-fold higher risk of rupture for growing-versus-nongrowing aneurysms. ${ }^{16}$ The 2015 AHA guidelines recommend a first follow-up study at 6-12 months after the initial discovery, followed by subsequent yearly or biennial follow-up (Class IIb; Level of Evidence C). ${ }^{8}$ However, the correlation between growth and rupture is relatively poor in small and tiny aneurysms. ${ }^{3}$ While Villablanca et $\mathrm{al}^{16}$ reported a good correlation for aneurysms of $<7 \mathrm{~mm}$, other studies by Sonobe et $\mathrm{al}^{23}$ and Bor et al did not. ${ }^{24}$

Respondents overwhelmingly favored MRA for imaging follow-up of small aneurysms, though $20 \%$ preferred CTA. There is considerable variability in the published literature on the optimal imaging technique used to assess growth in UIAs. ${ }^{3,17}$ Although there is literature on the sensitivity and specificity of CTA and MRA for the detection of aneurysms, with DSA considered the criterion standard, there is a paucity of evidence on their accuracy for growth detection. Most studies do not describe interobserver reliability of measurements. Some studies used the average between 2 readers for analysis. ${ }^{25}$ Other studies reported that the first and last imaging of each patient were assessed for growth in a single session by the same researcher to avoid interobserver and intraobserver reliability. ${ }^{24}$

For assessing size, the change in the maximum dimension was chosen by $90 \%$ (205/227), while $24 \%$ (54/227) also chose aneurysm height. Dome-to-neck ratio, aspect ratio, and size ratio were chosen by fewer respondents. A similar degree of heterogeneity was seen in responses to criteria used to assess growth. Most respondents $(73 \%)$ chose growth of $>1 \mathrm{~mm}$ in at least 1 direction, but $16 \%(37 / 227)$ chose a $0.5-\mathrm{mm}$ increase as clinically significant. No statistically significant difference was found in responses between diagnostic neuroradiologists and neurointerventional radiologists/endovascular neurosurgeons in size measurements on surveillance imaging and criteria used to define growth.

This variability in the definition of growth was also seen in studies reporting growth in UIAs and becomes even more significant for small UIAs. ${ }^{3,17}$ Very few studies have used different cri- 
teria for defining growth in aneurysms of $<5 \mathrm{~mm}$ compared with larger aneurysms. ${ }^{26}$ Mehan et $\mathrm{al}^{27}$ selected $2 \mathrm{~mm}$ as the criterion for growth in any dimension between CTA examinations because of the high degree of imprecision with smaller measurements.

In addition to size, retrospective studies have identified several morphologic parameters as potential predictors of rupture: aspect ratio (height/neck), ${ }^{28}$ the bottleneck factor (dome/neck ratio), ${ }^{29}$ height/width ratio, ${ }^{29}$ volume-to-ostium area ratio, ${ }^{30}$ and size ratio. ${ }^{31}$ However, the indices reported were measured after aneurysm rupture, and the results are conflicting. ${ }^{32-34}$ There is substantial variability in the definition and application of aneurysm morphology with multiple criteria, with the Unruptured Cerebral Aneurysm Study criteria reportedly having higher reliability than the ISUIA criteria. ${ }^{35}$ Alternative aneurysm size definitions have been shown to have significant impact on prediction performance and optimal threshold values. ${ }^{32}$ In a prospective study, dome-toneck ratio and multilobar morphology were found to be risk factors for growth in UIAs. ${ }^{24}$ Aneurysm volume was recently reported to predict future rupture in the only long-term prospective study for UIAs. ${ }^{34}$

A total of 101/227 (44\%) respondents thought that small aneurysms should be routinely treated with coiling or clipping. Roughly $85 \%$ thought that surveillance imaging to assess growth should at least be annually. Although only 20\% (44/227) of respondents thought that UIAs can rupture $\geq 10$ years after they are found, nearly $60 \%$ opted for indefinite, life-long imaging surveillance. Only 20\% (46/227) responded that only high-risk aneurysms should be treated or have routine imaging surveillance. Age and smoking history were chosen by more neurointerventional radiologists/endovascular neurosurgeons as criteria to treat small aneurysms. These have been shown to be risk factors for growth and rupture of UIAs. ${ }^{8}$

In a 2015 international survey of 203 neurosurgeons, most endorsed treatment of all asymptomatic aneurysms regardless of size. ${ }^{12}$ A more recent North American study showed that $11 \%$ of treating physicians always or usually recommended treatment of the anterior circulation aneurysms of $<5 \mathrm{~mm}$ without a family or personal history of SAH. ${ }^{13}$ Another $30 \%$ sometimes treated these small aneurysms $(40 \%-60 \%$ of the time). A third of the respondents in our survey were practicing neurointerventionalists who treated aneurysms in clinical practice. The utility and cost-effectiveness of routine treatment or close imaging surveillance of all small UIAs are not well-established. ${ }^{36}$

Surveillance imaging may not detect growth if the intervals are too far apart. Other studies have suggested that aneurysms might bleed shortly after formation, and most aneurysms without early rupture may remain stable for life, thereby questioning the rationale for prophylactic treatment of incidental small UIAs. ${ }^{37}$ Significant heterogeneity in imaging follow-up protocols has been demonstrated in both untreated and treated aneurysms. ${ }^{13,38}$

The AHA/ASA guidelines recommend that patients with documented enlargement during follow-up should be offered treatment in the absence of prohibitive comorbidities (Class I; Level of Evidence B). Long-term follow-up imaging may be considered after treatment, given the combined risk of aneurysm recurrence and de novo aneurysm formation (Class IIb; Level of Evidence B). The timing and duration of follow-up is, however, not defined for treated and untreated aneurysms, and additional investigation has been deemed necessary. ${ }^{8}$

Aneurysm growth is probably an irregular and discontinuous process, with potentially long periods of stability interjected with brief periods of wall instability, permitting growth or aneurysm rupture. ${ }^{19,24,39}$ Some studies have suggested a decreased risk of aneurysm rupture after 5 years. However, in the only long-term study of patients diagnosed with UIAs between 1956 and 1978 and prospectively followed, the median time between diagnosis and a subsequent aneurysm rupture was 10.6 years (range, 1.2-24.4 years), with a median follow-up of 24.4 years. ${ }^{34}$

The cost-effectiveness of screening for asymptomatic UIAs depends on multiple factors: the likelihood of UIA detection in the study population; the sensitivity and specificity of the imaging technique; the risk of rupture in conservatively followed UIAs; the cost, morbidity, and mortality associated with treatment (such as coiling or clipping); and the risk of subsequent rupture after aneurysm treatment. The AHA/ASA guidelines recommend screening in patients with $\geq 2$ family members with intracranial aneurysms or subarachnoid hemorrhage and in patients with a history of autosomal polycystic kidney disease (Class I; Level of Evidence B). ${ }^{8}$

There are several limitations in interpreting the results of this survey. The survey was designed to study general imaging practices and perceptions among specialists in neuroimaging. Each aneurysm has unique characteristics, and each patient needs individual consideration. The survey did not address consideration of specific features such as aneurysm location that may significantly impact treatment decisions. An overrepresentation of neurointerventional radiologists (29\%) in the respondents might bias the results toward aggressive, routine treatment of small UIAs. The study was also subject to inherent limitations of survey methodology.

\section{CONCLUSIONS}

This survey of practicing neuroradiologists and neurointerventionalists demonstrates significant variability in the perceptions and surveillance practices for small UIAs. This is not surprising given the heterogeneity in the current guidelines and literature coupled with the lack of a clear understanding of the natural history of small UIAs. Better evidence is needed to determine the optimal imaging criteria to assess aneurysm growth and rupture risk. By increasing awareness of the considerable heterogeneity in clinical practice, this study highlights the gap in radiologists' perspectives and the need for standardization of surveillance and treatment practices for patients with UIAs.

\section{REFERENCES}

1. Vlak MH, Algra A, Brandenburg R, et al. Prevalence of unruptured intracranial aneurysms, with emphasis on sex, age, comorbidity, country, and time period: a systematic review and meta-analysis. Lancet Neurol 2011;10:626-36 CrossRef Medline

2. Qureshi AI, Suri MF, Nasar A, et al. Trends in hospitalization and mortality for subarachnoid hemorrhage and unruptured aneurysms in the United States. Neurosurgery 2005;57:1-8; discussion 1-8 Medline

3. Malhotra A, Wu X, Forman HP, et al. Growth and rupture risk of small unruptured intracranial aneurysms: a systematic review. Ann Intern Med 2017;167:26-33 CrossRef Medline 
4. Steiner T, Juvela S, Unterberg A, et al; European Stroke Organization. European Stroke Organization guidelines for the management of intracranial aneurysms and subarachnoid haemorrhage. Cerebrovasc Dis (Basel, Switzerland) 2013;35:93-112 CrossRef Medline

5. Go AS, Mozaffarian D, Roger VL, et al; American Heart Association Statistics Committee and Stroke Statistics Subcommittee. Heart disease and stroke statistics: 2014 update-a report from the American Heart Association. Circulation 2014;129:e28-92 CrossRef Medline

6. Wiebers DO, Whisnant JP, Huston J 3rd, et al; International Study of Unruptured Intracranial Aneurysms Investigators. Unruptured intracranial aneurysms: natural history, clinical outcome, and risks of surgical and endovascular treatment. Lancet 2003;362:103-10 CrossRef Medline

7. Morita A, Kirino T, Hashi K, et al; UCAS Japan Investigators. The natural course of unruptured cerebral aneurysms in a Japanese cohort. N Engl J Med 2012;366:2474-82 CrossRef Medline

8. Thompson BG, Brown RD Jr, Amin-Hanjani S, et al; American Heart Association Stroke Council, Council on Cardiovascular and Stroke Nursing, and Council on Epidemiology and Prevention, American Heart Association, American Stroke Association. Guidelines for the management of patients with unruptured intracranial aneurysms: a guideline for healthcare professionals from the American Heart Association/American Stroke Association. Stroke 2015;46:2368400 CrossRef Medline

9. Murayama $\mathrm{Y}$, Takao H, Ishibashi T, et al. Risk analysis of unruptured intracranial aneurysms: prospective 10-year cohort study. Stroke 2016;47:365-71 CrossRef Medline

10. Wardlaw JM, White PM. The detection and management of unruptured intracranial aneurysms. Brain 2000;123(Pt 2):205-21 CrossRef Medline

11. Wong GK, Teoh J, Chan EK, et al. Intracranial aneurysm size responsible for spontaneous subarachnoid haemorrhage. Br J Neurosurg 2013;27:34-39 CrossRef Medline

12. Alshafai N, Falenchuk O, Cusimano MD. Practices and controversies in the management of asymptomatic aneurysms: results of an international survey. Br J Neurosurg 2015;29:758 -64 CrossRef Medline

13. Fargen KM, Soriano-Baron HE, Rushing JT, et al. A survey of intracranial aneurysm treatment practices among United States physicians. J Neurointerv Surg 2018;10:44-49 CrossRef Medline

14. Wermer MJ, van der Schaaf IC, Algra A, et al. Risk of rupture of unruptured intracranial aneurysms in relation to patient and aneurysm characteristics: an updated meta-analysis. Stroke 2007;38: 1404-10 CrossRef Medline

15. Güresir E, Vatter H, Schuss P, et al. Natural history of small unruptured anterior circulation aneurysms: a prospective cohort study. Stroke 2013;44:3027-31 CrossRef Medline

16. Villablanca JP, Duckwiler GR, Jahan R, et al. Natural history of asymptomatic unruptured cerebral aneurysms evaluated at $C T$ angiography: growth and rupture incidence and correlation with epidemiologic risk factors. Radiology 2013;269:258-65 CrossRef Medline

17. Backes D, Rinkel GJ, Laban KG, et al. Patient- and aneurysm-specific risk factors for intracranial aneurysm growth: a systematic review and meta-analysis. Stroke 2016;47:951-57 CrossRef Medline

18. Connolly ES Jr, Rabinstein AA, Carhuapoma JR, et al; American Heart Association Stroke Council, Council on Cardiovascular Radiology and Intervention, Council on Cardiovascular Nursing, Council on Cardiovascular Surgery and Anesthesia, Council on Clinical Cardiology. Guidelines for the management of aneurysmal subarachnoid hemorrhage: a guideline for healthcare professionals from the American Heart Association/American Stroke Association. Stroke 2012;43:1711-37 CrossRef Medline

19. Chmayssani M, Rebeiz JG, Rebeiz TJ, et al. Relationship of growth to aneurysm rupture in asymptomatic aneurysms $\leq 7 \mathrm{~mm}$ : a systematic analysis of the literature. Neurosurgery 2011;68:1164-71; discussion 1171 CrossRef Medline

20. Li MH, Chen SW, Li YD, et al. Prevalence of unruptured cerebral aneurysms in Chinese adults aged 35 to 75 years: a cross-sectional study. Ann Intern Med 2013;159:514-21 CrossRef Medline
21. Juvela S, Poussa K, Lehto H, et al. Natural history of unruptured intracranial aneurysms: a long-term follow-up study. Stroke 2013; 44:2414-21 CrossRef Medline

22. Ishibashi T, Murayama $Y$, Urashima M, et al. Unruptured intracranial aneurysms: incidence of rupture and risk factors. Stroke 2009; 40:313-16 CrossRef Medline

23. Sonobe M, Yamazaki T, Yonekura M, et al. Small unruptured intracranial aneurysm verification study: SUAVe study, Japan. Stroke 2010;41:1969-77 CrossRef Medline

24. Bor AS, Tiel Groenestege AT, terBrugge KG, et al. Clinical, radiological, and flow-related risk factors for growth of untreated, unruptured intracranial aneurysms. Stroke 2015;46:42-48 CrossRef Medline

25. Burns JD, Huston J 3rd, Layton KF, et al. Intracranial aneurysm enlargement on serial magnetic resonance angiography: frequency and risk factors. Stroke 2009;40:406-11 CrossRef Medline

26. Ferns SP, Sprengers ME, van Rooij WJ, et al. De novo aneurysm formation and growth of untreated aneurysms: a 5-year MRA follow-up in a large cohort of patients with coiled aneurysms and review of the literature. Stroke 2011;42:313-18 CrossRef Medline

27. Mehan WA Jr, Romero JM, Hirsch JA, et al. Unruptured intracranial aneurysms conservatively followed with serial CT angiography: could morphology and growth predict rupture? J Neurointerv Surg 2014;6:761-66 CrossRef Medline

28. Nader-Sepahi A, Casimiro M, Sen J, et al. Is aspect ratio a reliable predictor of intracranial aneurysm rupture? Neurosurgery 2004;54: 1343-47; discussion 1347-48 CrossRef Medline

29. Hoh BL, Sistrom CL, Firment CS, et al. Bottleneck factor and heightwidth ratio: association with ruptured aneurysms in patients with multiple cerebral aneurysms. Neurosurgery 2007;61:716-22; discussion 722-23 CrossRef Medline

30. Yasuda R, Strother CM, Taki W, et al. Aneurysm volume-to-ostium area ratio: a parameter useful for discriminating the rupture status of intracranial aneurysms. Neurosurgery 2011;68:310-17; discussion 317-18 CrossRef Medline

31. Dhar S, Tremmel M, Mocco J, et al. Morphology parameters for intracranial aneurysm rupture risk assessment. Neurosurgery 2008; 63:185-96; discussion 196-97 CrossRef Medline

32. Lauric A, Baharoglu MI, Malek AM. Ruptured status discrimination performance of aspect ratio, height/width, and bottleneck factor is highly dependent on aneurysm sizing methodology. Neurosurgery 2012;71:38-45 CrossRef Medline

33. Lauric A, Baharoglu MI, Gao BL, et al. Incremental contribution of size ratio as a discriminant for rupture status in cerebral aneurysms: comparison with size, height, and vessel diameter. $\mathrm{Neu}$ rosurgery 2012;70:944-51; discussion 951-52 CrossRef Medline

34. Juvela S, Korja M. Intracranial aneurysm parameters for predicting a future subarachnoid hemorrhage: a long-term follow-up study. Neurosurgery 2017;81:432-40 CrossRef Medline

35. Suh SH, Cloft HJ, Huston J 3rd, et al. Interobserver variability of aneurysm morphology: discrimination of the daughter sac. J Neurointerv Surg 2016;8:38-41 CrossRef Medline

36. Malhotra $\mathrm{A}, \mathrm{Wu} \mathrm{X}$, Forman $\mathrm{HP}$, et al. Management of tiny unruptured intracranial aneurysms: a comparative effectiveness analysis. JAMA Neurol 2018;75:27-34 CrossRef Medline

37. Sato K, Yoshimoto Y. Risk profile of intracranial aneurysms: rupture rate is not constant after formation. Stroke 2011;42:3376-81 CrossRef Medline

38. Gupta R, Griessenauer CJ, Adeeb N, et al. Evaluating imaging follow-up strategies and costs of unruptured intracranial aneurysms treated with endovascular techniques: a survey of academic neurovascular centers in the United States. World Neurosurg 2016;94: 360-67 CrossRef Medline

39. Koffijberg H, Buskens E, Algra A, et al. Growth rates of intracranial aneurysms: exploring constancy. J Neurosurg 2008;109:176-85 CrossRef Medline 